\title{
Desain dan Implementasi Konverter DC-DC Rasio Tinggi Berbasis Pensaklaran Kapasitor dan Induktor Terkopel untuk Aplikasi pada Photovoltaic
}

\author{
Gusti Rinaldi Zulkarnain, Dedet Candra Riawan, ST., M.Eng., Ph.D dan Prof. Ir. Mochamad Ashari, \\ M.Eng.,Ph.D \\ Jurusan Teknik Elektro, Fakultas Teknologi Industri, Institut Teknologi Sepuluh Nopember (ITS) \\ Jl. Arief Rahman Hakim, Surabaya 60111 \\ e-mail:dedet@ee.its.ac.id; ashari@ee.its.ac.id; gusti.rinaldi.zulkarnain12@mhs.ee.its.ac.id
}

\begin{abstract}
Abstrak-Seiring dengan berkembangnya pembangkit listrik yang menggunakan photovoltaic sebagai salah satu energi terbarukan, maka berdampak kepada perkembangan teknologi konverter. Tegangan output dari photovoltaic masih perlu ditingkatkan agar mampu dihubungkan pada sistem grid. Salah satu pengembangan topologi konverter boost untuk aplikasi keluaran photovoltaic yaitu konverter DC-DC rasio tinggi berbasis pensaklaran kapasitor dan induktor terkopel. Konverter ini merupakan pengembangan dari konverter gabungan boost-flyback yang ditambahkan rangkaian pensaklaran kapasitor. Kelebihan dari konverter ini adalah memiliki rasio konversi dan efisiensi yang tinggi. Konverter ini mampu menjaga tegangan output konstan ketika tegangan inputnya berubah-ubah. Konverter ini sangan cocok diaplikasikan pada sumber energi alternatif yang menghasilkan tegangan DC rendah seperti photovoltaic.
\end{abstract}

Kata Kunci-Induktor-Kopel, Konverter DC-DC Rasio Tinggi, Pensaklaran Kapasitor, Photovoltaic.

\section{PENDAHULUAN}

$\mathrm{S}_{\mathrm{ta}}^{\mathrm{A}}$ AAT ini sistem pembangkit menggunakan energi terbarukan banyak dikembangkan di berbagai daerah. Salah satu sistem energi terbarukan yang banyak digunakan yaitu sel surya. Sel surya atau sering disebut photovoltaic merupakan alat yang digunakan untuk mengkonversi cahaya matahari menjadi energi listrik. Intensitas cahaya matahari sangat berpengaruh terhadap sistem kerja sel surya. Hal tersebut mengakibatkan tegangan dan daya output yang dihasilkan sel surya bervariasi. Masih rendahnya tegangan output sel surya mengakibatkan sel surya tidak bisa langsung dihubungkan pada sistem grid. Sehingga dibutuhkan konverter DC-DC yang memiliki rasio konversi tinggi untuk menaikkan tegangan output sel surya agar bisa dihubungkan pada sistem grid [1].

Konverter boost adalah konverter DC-DC yang digunakan untuk meningkatkan tegangan DC output sel surya dengan cara mengatur duty cycle. Semakin tinggi tegangan rasio konversi maka semakin besar nilai duty cycle [2]. Namun dalam prakteknya tingginya nilai duty cycle tidak sesuai dengan kondisi dari peralatan yang ada seperti meningkatnya rugi-rugi konduksi dan tingginya arus transien pada sistem pensaklaran. Selain itu, semakin besar nilai duty cycle maka mengakibatkan adanya masalah reverse recovery, efisiensi rendah dan pengaruh elektromagnetik (EMI) [3]. Konverter DC-DC merupakan peralatan yang menghasilkan

Beberapa konverter seperti konverter forward dan flyback telah digunakan untuk mendapatkan rasio konversi yang tinggi dengan mengatur perbandingan belitan menggunakan trafo frekuensi tinggi atau sering disebut induktor terkopel. Konverter ini hanya bergantung pada perbandingan belitan antara sisi primer dan sekunder dari induktor terkopel. Sehingga sistem pensaklaran utama akan mengalami tegangan spike yang tinggi dan banyak kehilangan daya yang diakibatkan oleh induktansi bocor dari induktor terkopel [4]. Rangkaian snubber digunakan untuk mengurangi permasalahan tegangan spike pada sistem pensaklaran. Namun, hal tersebut menambah biaya pembuatan serta mengurangi efisiensi dari peralatan.

Berbagai topologi dapat digunakan untuk memperoleh efisiensi dan rasio konversi yang tinggi tanpa harus beroperasi pada duty cycle yang tinggi. Konverter DC-DC dengan menggunakan induktor terkopel telah banyak digunakan untuk meningkatkan rasio konversi dengan cara mengatur perbandingan lilitan pada sisi primer dan sekunder [5]. Penambahan rangkaian clamper dapat mengurangi tegangan spike pada sistem pensaklaran [6]. Peningkatan rasio pada konverter juga dapat diperoleh dengan menggunakan penskalaran kapasitor atau teknik voltage-lift.

Pada Tugas Akhir ini akan diusulkan konverter DC-DC penguat tegangan tinggi berbasis teknik pensaklaran kapasitor dan induktor terkopel untuk memperoleh rasio konversi yang tinggi. Induktor terkopel akan diopersikan sebagai konverter flyback. Kapasitor akan charge secara parallel dan kemudian dishrage secara seri oleh bagian sekunder dari induktor terkopel. Disamping itu, pada sisi sekunder induktor terkopel dapat mengurangi masalah reverse recovery pada diode sehingga rugi-rugi dapat dikurangi. Rangkaian passive clamp ditambahkan untuk mempertahankan tegangan pada pensklaran dan merecycle energi dari induktor bocor pada induktor terkopel sehingga diperoleh efisiensi dan rasio konversi yang tinggi.

\section{URAIAN PENELITIAN}

\section{A. Konfigurasi Sistem}

Pada gambar 1 menunjukkan blok diagram keseluruhan dari Konverter DC-DC Rasio Tinggi Berbasis Pensaklaran Kapasitor dan Induktor Terkopel. Blok diagram tersebut terdiri dari sumber DC 30-35 volt, konverter DC-DC rasio tinggi berbasis pensaklaran kapasitor dan induktor terkopel, beban 100 Watt, driver mosfet dan PWM. Konverter ini bekerja pada frekuensi $62,5 \mathrm{kHz}$. Tegangan output dinaikkan menjadi $350 \mathrm{~V}$ dengan duty cycle sebesar 0,48. Keluaran dari 
konverter ini dapat dimanfaatkan untuk menyuplai DC-AC inverter yang kemudian dihubungkan pada sistem grid. Pada konverter dilengkapai dengan sistem tegangan output konstan. Pengaturan tegangan keluaran konstan pada konverter dengan cara mengatur nilai duty cycle dengan menggunakan kontroler PI. Penentuan konstanta PI dengan cara trial and error.

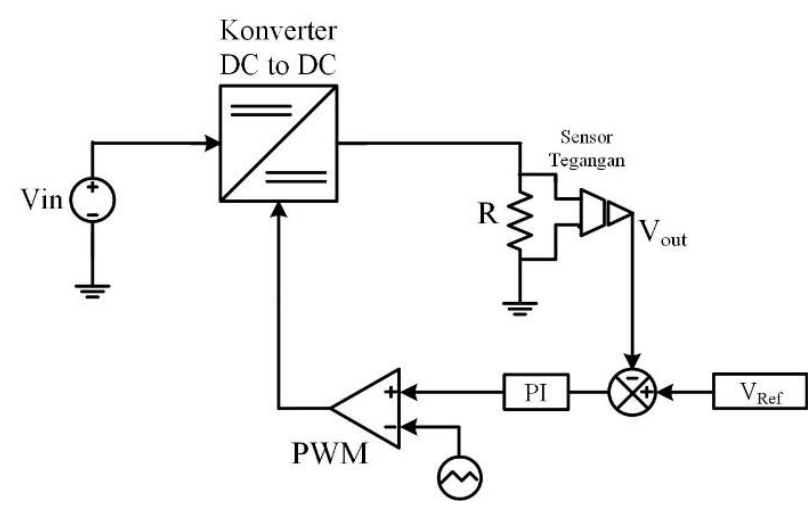

Gambar 1. Blok diagram rangkaian konverter DC-DC Rasio Tinggi Berbasis Pensaklaran Kapasitor dan Induktor Terkopel.

\section{B. Konverter DC-DC Rasio Tinggi Berbasis Pensaklaran Kapasitor dan Induktor Terkopel}

Topologi konverter DC-DC rasio tinggi berbasis pensaklaran kapasitor dan induktor terkopel ditunjukkan pada gambar 2. Topologi konverter terdiri dari 3 bagian utama, yaitu induktor terkopel, voltage clamp, pensaklaran kapasitor.

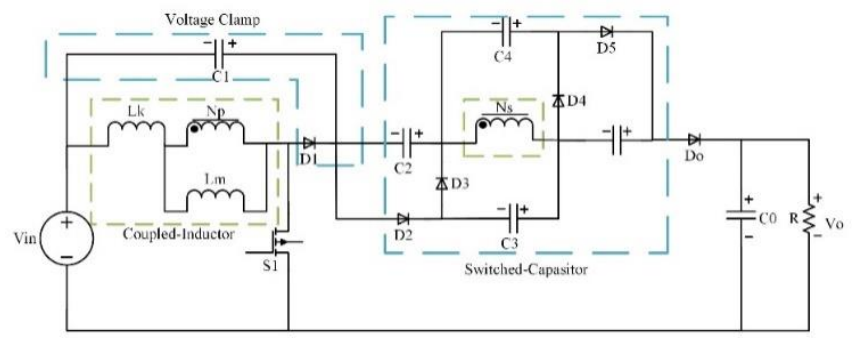

Gambar 2. Rangkaian Konverter DC- DC Rasio Tinggi Berbasis Pensaklaran Kapasitor dan Induktor Terkopel

Rangkaian konverter DC-DC rasio tinggi berbasis pensaklaran kapasitor dan induktor terkopel merupakan rangkaian gabungan yang terdiri dari Integrated BoostFlyback Converter (IBFC) yang ditambahkan dengan rangkaian voltage-lift berupa rangkaian pensaklaran kapasitor untuk meningkatkan rasio konversi dari konverter. Kapasitor pada sisi sekunder induktor terkopel akan charge secara seri dan kemudian discharge secara paralel. Voltage clamp berfungsi untuk merecycle energi dari induktor bocor.

Induktor terkopel dimodelkan sebagai trafo ideal dengan induktor magnetisasi $\mathrm{L}_{\mathrm{m}}$ dan induktor bocor $\mathrm{L}_{\mathrm{k}}$ pada sisi primer induktor kopel. Energi pada induktor bocor akan direcycle pada kapasitor $\mathrm{C}_{1}$. Kapasitor $\mathrm{C}_{2}, \mathrm{C}_{3}, \mathrm{C}_{4}$ dan $\mathrm{C}_{5}$ berfungsi sebagai rangakian pensaklaran kapasitor. Dengan menggunakan dua metode diatas maka konverter memiliki rasio konversi tinggi.

\section{Mode Operasi Konverter}

Konverter DC-DC rasio tinggi berbasis pensaklaran kapasitor dan induktor terkopel memiliki lima mode operasi dalam satu periode pensaklaran. Analisis mode operasi konverter dilakukan dengan mengasumsikan bahwa semua komponen dianggap ideal kecuali induktor terkopel yang dimodelkan dengan induktor bosor pada sisi primer. Tegangan pada kapasitor dianggap konstan dan konverter bekerja secara continuous conduction mode (CCM) atau arus ILM selalu lebih besar dari nol [7]. Bentuk gelombang karakteristik dari konverter dapat dilihat pada gambar 3 di bawah ini.

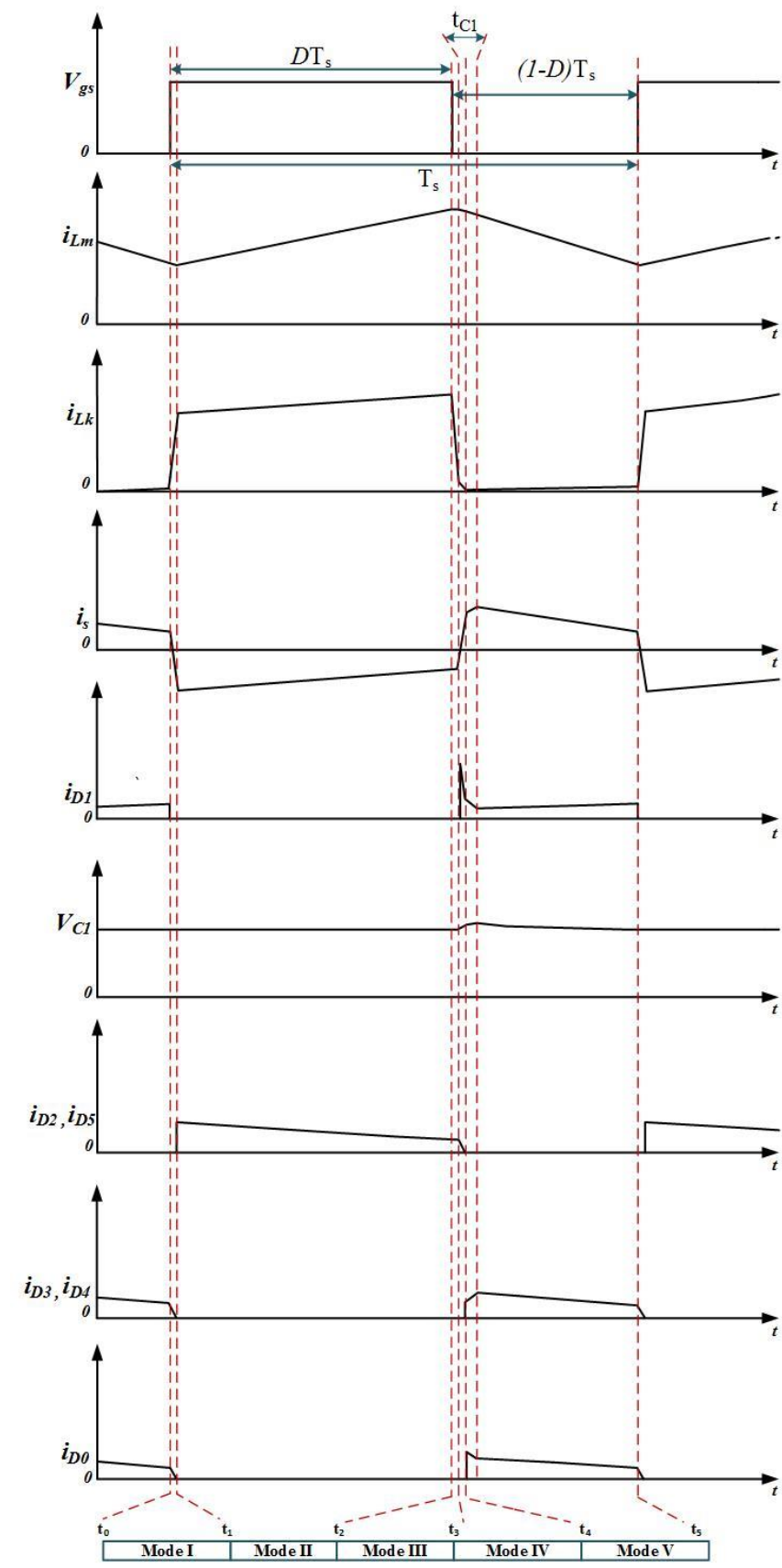

Gambar 3. Bentuk Gelombang Karakteristik dari Konverter.

\section{Mode operasi $1\left(\mathrm{t}_{0^{-}} \mathrm{t}_{1}\right)$}

Pada saat $\mathrm{t}_{0}-\mathrm{t}_{1}$, switch $\mathrm{S}_{1}$ konduksi dan mengawali mode ON dari konverter. Dioda $\mathrm{D}_{1}, \mathrm{D}_{2}$ dan $\mathrm{D}_{5}$ dalam kondisi reverse-biased sedangkan dioda $\mathrm{D}_{3}, \mathrm{D}_{4}$ dan Do dalam kondisi forward-biased. Arus primer $\mathrm{I}_{\mathrm{Lk}}$ akan meningkat secara linear, kemudian induktor magnetisasi $\mathrm{L}_{\mathrm{m}}$ akan mulai untuk menyimpan energi dari sumber DC $\mathrm{V}_{\text {in. }}$ Pada sisi sekunder induktor kopel, tegangan $\mathrm{V}_{\mathrm{L} 2}, \mathrm{~V}_{\mathrm{C} 2}$, dan $\mathrm{V}_{\mathrm{C} 5}$ dihubungkan secara seri untuk charge kapasitor $\mathrm{C}_{\mathrm{O}}$ dan menyalurkan energi ke beban R. Operasi pada mode ini berakhir ketika nilai arus yang mengalir pada $\mathrm{D}_{\mathrm{O}}\left(\mathrm{I}_{\mathrm{DO}}\right)$ bernilai nol. Gambar 4 menunjukkan aliran arus pada mode operasi I. 


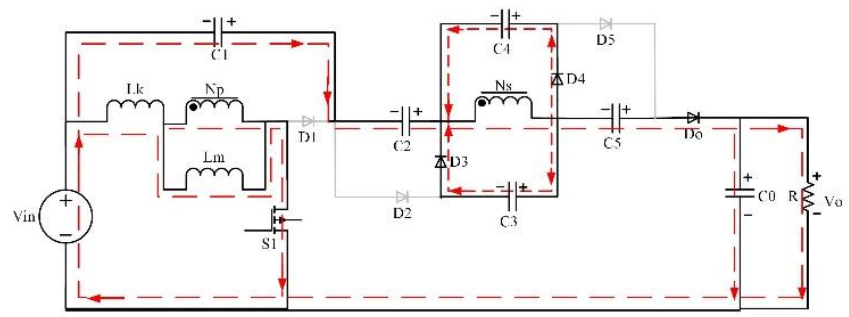

Gambar 4. Mode Operasi I $\left(\mathrm{t}_{0}-\mathrm{t}_{1}\right)$

2. Mode operasi $2\left(\mathrm{t}_{1}-\mathrm{t}_{2}\right)$

Mode operasi II pada konverter merupakan mode operasi dengan waktu yang panjang. Pada mode operasi ini sakelar tetap dalam kondisi ON. Dioda $\mathrm{D}_{1}, \mathrm{D}_{2}, \mathrm{D}_{3}$ dan $\mathrm{D}_{\mathrm{O}}$ dalam kondisi reverse biased sedangkan diode $\mathrm{D}_{2}$ dan $\mathrm{D}_{5}$ dalam kondisi forward biased. Aliran arus pada konverter dapat dilihat pada gambar 5. Induktor magnetisasi menyimpan energi dari sumber input $\mathrm{V}_{\text {in. }}$ Pada sisi sekunder, energi pada couple induktor dan kapasitor $\mathrm{C}_{3}$ dan $\mathrm{C}_{4}$ akan digunakan untuk mengisi kapasitor $\mathrm{C}_{2}$ dan $\mathrm{C}_{5}$ secara bersamaan. Beban $\mathrm{R}$ akan disuplai oleh kapasitor $\mathrm{C}_{\mathrm{O}}$. Mode ini berakhir ketika sakelar $\mathrm{S}_{1}$ dalam kondisi OFF atau $\mathrm{t}=\mathrm{t}_{2}$.

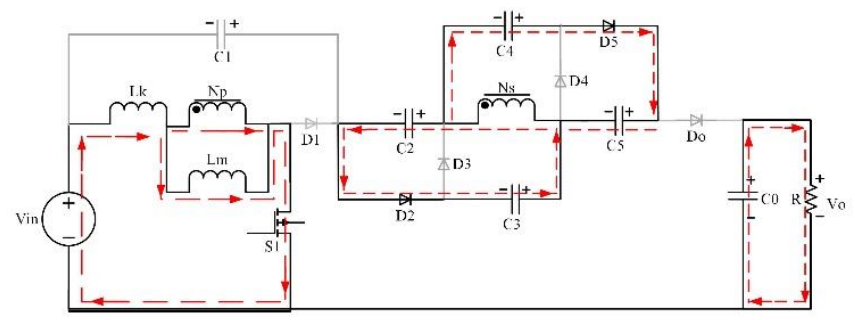

Gambar 5. Mode Operasi II $\left(\mathrm{t}_{1}-\mathrm{t}_{2}\right)$

3. Mode operasi $3\left(\mathrm{t}_{2}-\mathrm{t}_{3}\right)$

Mode operasi III dimulai ketika sakelar $\mathrm{S}_{1}$ dalam kondisi OFF. Dioda $\mathrm{D}_{1}, \mathrm{D}_{3}, \mathrm{D}_{4}$ dan $\mathrm{D}_{\mathrm{O}}$ dalam kondisi reverse biased. Sedangkan diode $\mathrm{D}_{2}$ dan $\mathrm{D}_{5}$ dalam kondisi forward biased. Arah aliran arus dapat dilihat pada gambar 6. Energi pada Induktor $\mathrm{L}_{\mathrm{k}}$ dan induktor magnetisasi $\mathrm{L}_{\mathrm{m}}$ akan dilepas pada kapasitor parasitic dari switch $\mathrm{S}_{1}$. Kapasitor $\mathrm{C}_{2}$ dan $\mathrm{C}_{5}$ akan diisi oleh sumber DC Vin melalui induktor kopel sisi sekunder. Beban R akan disupplai oleh kapasitor $\mathrm{C}_{\mathrm{O}}$. Ketika nilai tegangan pada kapasitor $V_{C 1}$ sama dengan $V_{\text {in }}+V_{d s}$ maka diode $\mathrm{D}_{1}$ akan konduksi dan operasi mode III akan berhenti.

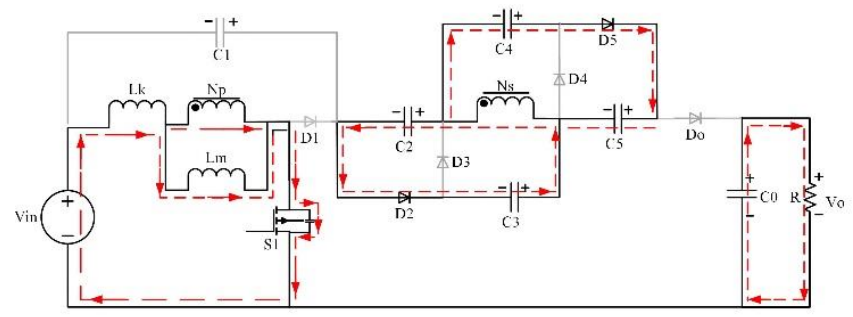

Gambar 6. Mode Operasi III $\left(\mathrm{t}_{2}-\mathrm{t}_{3}\right)$

4. Mode operasi $4\left(\mathrm{t}_{3}-\mathrm{t}_{4}\right)$

Selama interval mode operasi IV, sakelar $S_{1}$ tetap dalam kondisi OFF. Dioda $D_{1}, D_{2}$ dan $D_{5}$ dalam kondisi forward biased sedangkan diode $\mathrm{D}_{3}, \mathrm{D}_{4}$ dan $\mathrm{D}_{0}$ dalam kondisi reverse biased. Aliran arus dapat dilihat pada gambar 7. Energi dari induktor bocor Lk dan induktor magnetisasi Lm dilepas dan mengisi kapasitor C1. Sisi sekunder dari induktor terkopel akan charge kapasitor C2 dan C5 secara paralel sampai nilai arus sekunder Is bernilai sama dengan nol. Operasi berakhir saat dioda D2 dan D5 pada kondisi tegangan cut off yang kemudian diode akan reverse-biased.

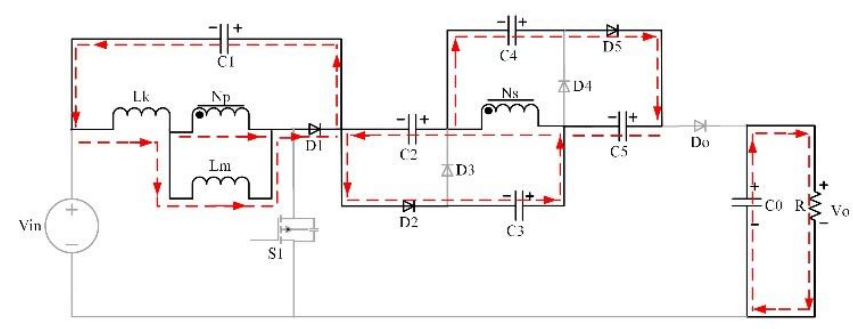

Gambar 7. Mode Operasi IV $\left(\mathrm{t}_{3}-\mathrm{t}_{4}\right)$

5. Mode operasi $5\left(t_{4}-t_{5}\right)$

Mode $\mathrm{V}$ merupakan mode dengan waktu yang panjang pada saat kodisi sakelar OFF. Dioda $\mathrm{D}_{1}, \mathrm{D}_{3}, \mathrm{D}_{4}$ dan Do dalam kondisi forward biased. Sedangkan diode $\mathrm{D}_{2}$ dan $\mathrm{D}_{5}$ dalam kondisi reverse biased. Arah aliran arus dapat dilihat pada gambar 8. Energi pada induktor $\mathrm{L}_{\mathrm{k}}$ dan $\mathrm{L}_{\mathrm{m}}$ akan dialirkan untuk mengisi kapasitor $\mathrm{C}_{1}$. Energi pada sisi sekunder induktor akan mengisi kapasitor $\mathrm{C}_{3}$ dan $\mathrm{C}_{4}$ secara paralel. Pada waktu bersamaan tegangan pada sisi sekunder induktor kopel $\mathrm{V}_{\mathrm{L} 2}$ akan terhubung secara seri dengan tegangan kapasitor $\mathrm{V}_{\mathrm{C} 2}$ dan $\mathrm{V}_{\mathrm{C} 5}$ sehingga energi dari tegangan input $\mathrm{V}_{\text {in }}, \mathrm{L}_{\mathrm{m}}, \mathrm{C}_{2}$ dan $\mathrm{C}_{5}$ akan mengisi kapasitor output Co dan beban R. Ketika arus pada sisi primer $\mathrm{I}_{\mathrm{Lk}}$ sama dengan arus diode $\mathrm{I}_{\text {Do }}$ kapasitor $\mathrm{C}_{1}$ akan melepas energinya. Mode $\mathrm{V}$ berakhir ketika sakelar kembali konduksi [8].

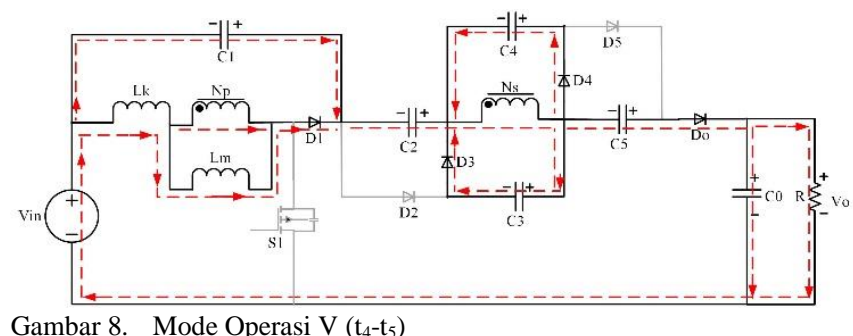

Gambar 8. Mode Operasi V $\left(\mathrm{t}_{4}-\mathrm{t}_{5}\right)$

D. Analisis Penurunan Rasio Konversi

Penurunan persamaan rasio konversi pada konverter menggunakan mode operasi terpanjang yaitu mode operasi 2 dan 5 [8]. Perbandingan belitan (N) dan koefisien kopling (k) dapat didefinisikan sebagai berikut:

$$
\begin{gathered}
N=\frac{n_{2}}{n_{1}} \\
k=\frac{L m}{L m+L k}
\end{gathered}
$$

Dimana $\mathrm{n}_{1}$ dan $\mathrm{n}_{2}$ merupakan jumlah belitan sisi primer dan sisi sekunder induktor kopel [7].

Pada mode operasi 2, sakelar $\mathrm{S}_{1}$ konduksi, sumber DC Vin melepas energinya ke induktor terkopel sisi primer. Kemudian sisi sekunder dari induktor terkopel akan terinduksi tegangan yang nilainya bergantung pada besarnya N. Sehingga, sesuai dengan gambar 5 dapat dituliskan persamaan:

$$
\begin{aligned}
& V_{L 1(O N)}=\frac{L m}{L m+L k}=k V_{i n} \\
& V_{L 2(O N)}=n V_{L 1(O N)}=n k V_{i n}
\end{aligned}
$$

Pada saat sakelar konduksi, kapasitor $\mathrm{C}_{2}$ dan $\mathrm{C}_{5}$ akan charge secara paralel oleh tegangan yang diinduksikan pada sisi sekunder induktor terkopel. Sehingga dapat dituliskan persamaan sebagai berikut: 


$$
\begin{aligned}
& V_{C 2}=V_{L 2(O N)}+V_{C 3} \\
& V_{C 5}=V_{L 2(O N)}+V_{C 4}
\end{aligned}
$$

Selanjutnya yaitu analisis kondisi konverter pada mode operasi 5 yaitu ketika sakelar S1 terbuka. Berdasarkan gambar 8, dapat dituliskan persamaan:

$$
\begin{gathered}
V_{L 2(\text { OFF })}=V_{\text {in }}+V_{C 1}+V_{C 2}+V_{C 5}-V_{o} \\
V_{L 2(\text { OFF })}=-V_{C 3}=-V_{C 4}
\end{gathered}
$$

Dengan menggunakan prinsip inductor volt-second balance pada induktor $\mathrm{L}_{\mathrm{k}}, \mathrm{L}_{1}$ dan $\mathrm{L}_{2}$ maka dapat diperoleh rasio konversi dari konverter. Berikut ini adalah analisis inductor volt-second balance pada $\mathrm{L}_{\mathrm{k}}$.

$$
\begin{gathered}
\int_{0}^{D T s} V_{L k(O N)} d t+\int_{D T s}^{T} V_{L k(O F F)} d t=0 \\
D T V_{L K(O N)}+(1-D) T V_{L K(O F F)}=0 \\
V_{L K(O F F)}=-\frac{D}{1-D}(1-k) V_{i n}
\end{gathered}
$$

Karena energi yang dilepas oleh induktor bocor akan sepenuhnya di-recycle oleh rangkaian voltage-clamp dan mengisi kapasitor $C_{1}[8]$. Energi yang dilepas saat DC1 dapat dituliskan:

$$
D_{C 1}=\frac{t_{C 1}}{T_{S}}=\frac{2(1-D)}{n+1}
$$

Selanjutnya substitusi persamaan (2.42) ke persamaan (11) maka diperoleh:

$$
V_{L K(O F F)}=\frac{-D(n+1)(1-k)}{2(1-D)} \operatorname{Vin}
$$

Dengan menggunakan prinsip yang sama pada induktor sisi primer yaitu L1 maka diperoleh persamaan sebagai berikut:

$$
\begin{gathered}
\int_{0}^{D T_{s}} V_{L 1(O N)} d t+\int_{D T s}^{T} V_{L 1(O F F)} d t=0 \\
D T V_{L 1(O N)}+(1-D) T V_{L 1(O F F)}=0 \\
V_{L L(O F F)}=\frac{-D}{1-D} k \text { Vin }
\end{gathered}
$$

Maka nilai induktor pada sisi sekunder induktor terkopel adalah

$$
V_{L 2(\text { OFF })}=\frac{-n D}{1-D} k \mathrm{Vin}
$$

Untuk memperoleh nilai tegangan pada C3 dan C4 maka substitusi persamaan (17) ke persamaan (18) sehingga diperoleh:

$$
V_{C 3}=V_{C 4}=\frac{n D}{1-D} k \mathrm{Vin}
$$

Untuk memperoleh nilai tegangan pada C2 dan C5 maka substitusi persamaan (18) ke persamaan (15) dan (16) sehingga diperoleh:

$$
V_{c 2}=V_{c 5}=\left(n k+\frac{n D k}{1-D}\right) V i n
$$

Tegangan kapasitor $\mathrm{C} 1$ merupakan penjumlahan tegangan pada Lk dan L1 pada saat kondisi sakelar terbuka.

$$
\begin{gathered}
V_{C 1}=V_{L K}-V_{L 1(\text { OFF })} \\
V_{C 1}=\frac{D(n+1)(1-k)}{2(1-D)} \operatorname{Vin}+\frac{D}{1-D} k \operatorname{Vin}
\end{gathered}
$$

Proses terakhir untuk mendapatkan rasio konversi yaitu dengan menggunakan prinsip inductor volt-second balance pada induktor terkopel sisi sekunder $\mathrm{L}_{2}$.

$$
\int_{0}^{D T s} V_{L 2(o n)} d t+\int_{D T s}^{T} V_{L 2(o f f)} d t=0
$$

Dengan melakukan substitusi persamaan (4) dan (7) ke persamaan (22) maka diperoleh:

$$
\text { DTnkVin }+(1-D) T\left[\operatorname{Vin}+V_{C 1}+V_{C 2}+V_{C 5}-V o\right]=0
$$

Kemudian substitusi persamaan (19) dan (21) ke persamaan (23) maka akan diperoleh rasio konversi dari konverter yaitu:

$$
\frac{V o}{V i n}=\frac{1+n k(2+D)}{1-D}+\frac{D}{1-D} \frac{(1-k)(n-1)}{2}
$$

Induktor magnetisasi Lm memiliki nilai yang jauh lebih besar dibandingkan dengan nilai $\mathrm{Lk}$, sehingga nilai $\mathrm{k}$ mendekati 1. Dengan mengaggap nilai $\mathrm{k}$ sama dengan 1 (induktor kopel ideal), maka persamaan (24) di atas dapat ditulis menjadi:

$$
M_{C C M}=\frac{V o}{V i n}=\frac{1+2 n+n D}{1-D}
$$

\section{DESAIN DAN IMPLEMENTASI}

A. Desain

Desain konverter bertujuan untuk menentukan parameter awal dari konverter.

Tabel 1.

Spesifikasi Awal Desain Konverter

\begin{tabular}{lc}
\hline \multicolumn{1}{c}{ Parameter } & Nilai \\
\hline Daya Output & $100 \mathrm{~W}$ \\
Tegangan Input & $30-35 \mathrm{~V}$ \\
Tegangan Output & $350 \mathrm{~V}$ \\
$\mathrm{~N}$ & 2 \\
Frekuensi Pensaklaran & 62500 \\
Ripple Tegangan Output & $0,01 \%$ \\
Ripple Arus Induktor Kopel & $20 \%$ \\
\hline \hline
\end{tabular}

Besarnya nilai duty cycle dan penguatan pada konverter yaitu:

$$
\begin{aligned}
& M=\frac{350}{30}=11.6667 \\
& D=\frac{350-30-2 \times 2 \times 30}{2 \times 30+350}=0,4878
\end{aligned}
$$

Nilai resistor yang digunakan sebagai beban konverter:

$$
R=\frac{V_{\text {out }}^{2}}{P_{\text {out }}} \frac{350^{2}}{100}=1225 \Omega
$$

Penentuan nilai induktor kopel yaitu dengan menggunakan arus yang melewati kopel induktor

$$
I_{L M}=\frac{(1+2 n+n D)^{2}}{R(1-D)^{2}} \operatorname{Vin} ; \Delta I_{L m}=\frac{D T}{L m} \operatorname{Vin}
$$




$$
I_{L M}=\frac{(1+2(2)+2(0.4878))^{2}}{1225(1-(0.4878))^{2}} 30=3,33 A
$$

Dengan ripple arus sebsesar $20 \%$ maka diperoleh nilai ripple sebesar:

$$
\Delta I_{L m}=0,2 \times 3,33=0,67 \mathrm{~A}
$$

Maka besarnya induktor magnetisasi yaitu: $\Delta$

$$
L m=\frac{0.5}{62500(0,67)} 30=358,2 u H
$$

Penentuan nilai kapasitor output yaitu:

$$
\begin{gathered}
C o=\frac{D}{R f \frac{\Delta V o}{V o}} \\
C_{O}=\frac{0,4878}{1225(62500)(0,0001)}=63,7 u F
\end{gathered}
$$

Penentuan nilai kapasitor $\mathrm{C}_{5}$ dan $\mathrm{C}_{2}$ yaitu:

$$
\begin{gathered}
C_{5}=C_{2}=\frac{(1-D)}{\Delta V_{C 2} f} \frac{V o}{R} \\
C_{5}=C_{2}=\frac{(1-0,4878)}{0,01(117,14)(62500)} \frac{350}{1225}=1,99 u F
\end{gathered}
$$

Penentuan nilai kapasitor $\mathrm{C}_{3}$ dan $\mathrm{C}_{4}$ yaitu:

$$
\begin{gathered}
C_{3}=C_{4}=\frac{(1-D)}{\Delta V_{C 3} f} \frac{V o}{R} \\
C_{3}=C_{4}=\frac{(1-0,4878)}{0,01(57,14)(62500)} \frac{350}{1225}=4,097 u F
\end{gathered}
$$

Penentuan nilai kapasitor $\mathrm{C}_{1}$ yaitu:

$$
\begin{gathered}
C_{1}=\frac{(1+2 n+n D)^{2}}{f R(1-D) \Delta V_{C 1}} \operatorname{Vin} \\
C_{1}=\frac{(1+2(2)+(2) 0,4878)^{2}}{62500(1225)(1-0,4878)(0,01)(28,57)} 30=95,6 u F
\end{gathered}
$$

\section{B. Implementasi}

Implementasi dilakukan untuk mengetahui kinerja konverter berdasarkan desain dan simulasi. Komponen yang digunakan saat implementasi:

Tabel 2.

Komponen yang digunakan saat Implementasi Konverter

\begin{tabular}{cc}
\hline \hline Komponen & Nilai \\
\hline Kopel Induktor $\mathrm{L}_{\mathrm{m}}$ & $395,29 \mathrm{uH}$ \\
$\mathrm{C}_{1}$ & $100 \mathrm{uF} / 200 \mathrm{~V}$ \\
$\mathrm{C}_{2}$ dan $\mathrm{C}_{5}$ & $2.2 \mathrm{uF} / 400 \mathrm{~V}$ \\
$\mathrm{C}_{3}$ dan $\mathrm{C}_{4}$ & $4.7 \mathrm{uF} / 400 \mathrm{~V}$ \\
$\mathrm{C}_{\mathrm{o}}$ & $100 \mathrm{uF} / 400 \mathrm{~V}$ \\
Dioda & MUR 1560 \\
MOSFET & IRFP 460 \\
\hline \hline
\end{tabular}

Sesuai dengan table 2, gambar 9 merupakan implementasi dari konverter DC-DC rasio tinggi berbasis pensaklaran kapasitor dan induktor terkopel.

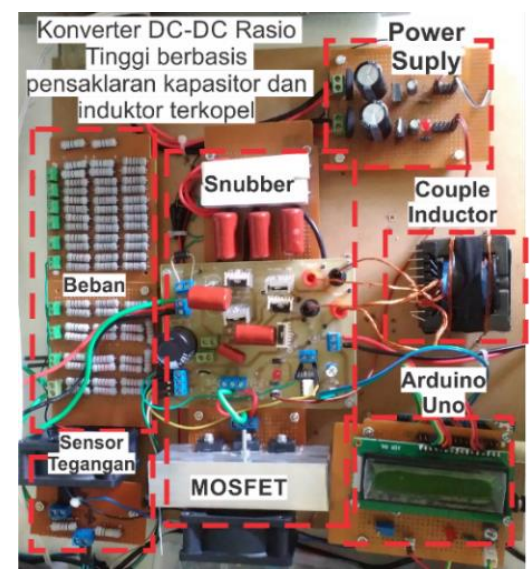

Gambar 9. Implementasi Konverter

\section{PENGUJIAN}

Gambar 10 dibawah ini merupakan grafik rasio konversi perbandingan hasil perhitungan dengan implementasi. Dari grafik dapat terlihat bahwa saat duty cycle rendah maka hasil implementasi mendekati dengan hasil perhitungan. Ketika duty cycle semakin tinggi maka hasil implementasi mengalami error yang semakin besar dibandingkan hasil perhitungan. Hal tersebut diakibatkan semakin besar nilai duty cycle maka arus yang mengalir pada konverter semakin besar sehingga drop tegangan disetiap komponen semakin besar sehingga selisih antara nilai implementasi dan perhitungan semakin besar.

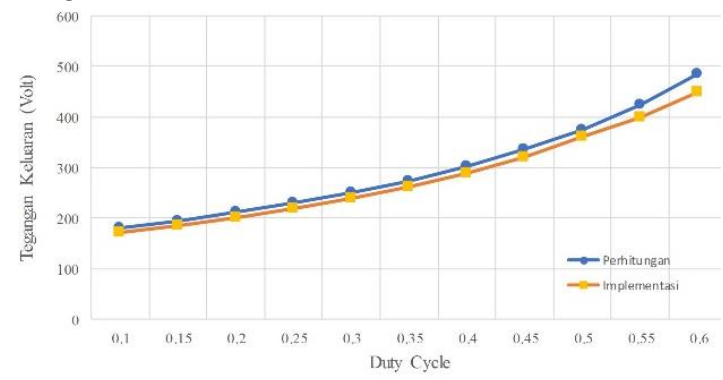

Gambar 10. Perbandingan Hasil Pengujian dan Perhitungan Rasio Konversi Konverter.

Bentuk sinyal pada kopel induktor sisi primer dapat dilihat pada gambar 11. Ketika saklar konduksi, arus pada sisi primer kopel akan meningkat dan tegangan pada sisi primer bernilai positif. Prinsip kerja ini sesuai dengan karakteristik dari konverter.

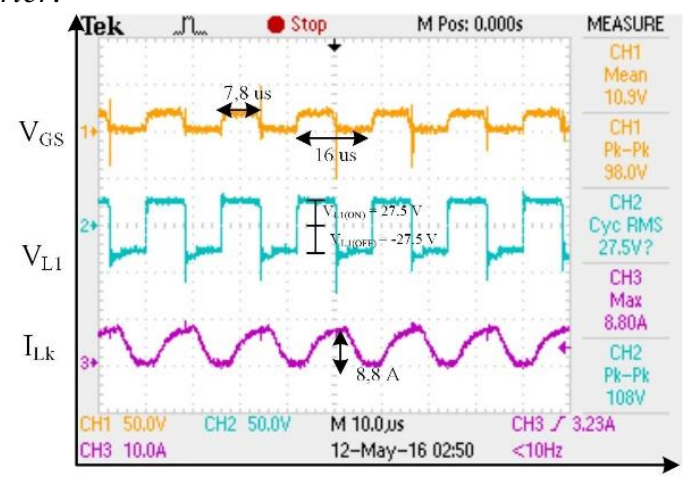

Gambar 11. Sinyal Tegangan dan Arus pada sisi Primer Kopel Induktor

Gambar 12 menunjukkan bentuk tegangan output konverter beserta ripplenya. Dari hasil implementasi, nilai ripple tegangan output konverter sebesar 0,018\%. Hal tersebut mendekati hasil desain dari konverter. Ketidak 
tepatan implementasi dengan desain disebabkan adanya factor ketidakidealan pada komponen.

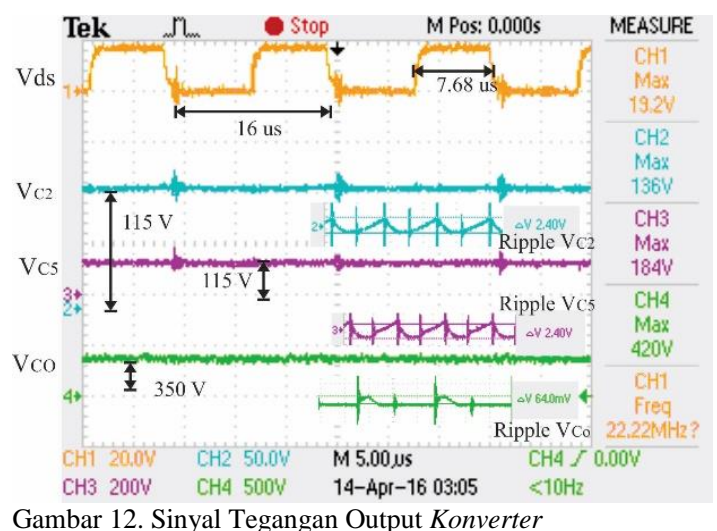

Efisiensi pada konverter dapat dilihat pada gambar 12 . Dari grafik tersebut dapat disimpulkan bahwa rata-rata efisiensi konverter sebesar $86 \%$. Efisiensi terbesar yaitu pada saat beban konverter sebesar $40 \mathrm{~W}$.

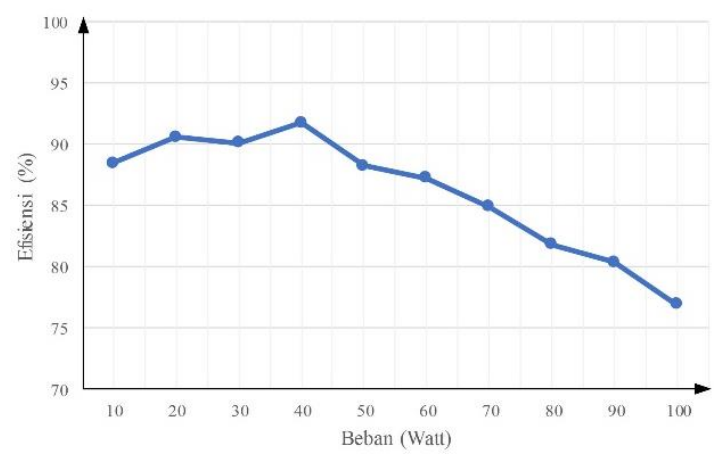

Gambar 12. Implementasi Konverter

Hasil pengujian menggunakan modul photovoltaic dapat dilihat pada gambar 13. Tegangan output mampu dipertahankan pada nilai $300 \mathrm{~V}$ saat pukul 08.00 - 13.00. Namun ketika pukul 13.00-15.00 tegangan output tidak bisa mencapai nilai $300 \mathrm{~V}$ dikarenakan daya yang dihasilkan oleh PV semakin turun akibat iradiasi matahari semakin menurun ketika menjelang sore hari dan suhu dari modul photovoltaic semakin meningkat.

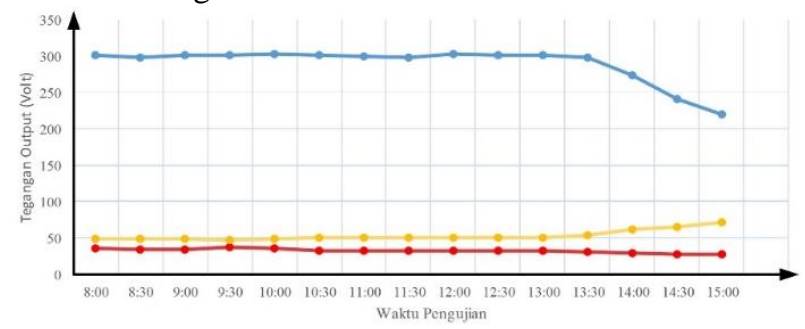

Gambar 13. Implementasi Konverter

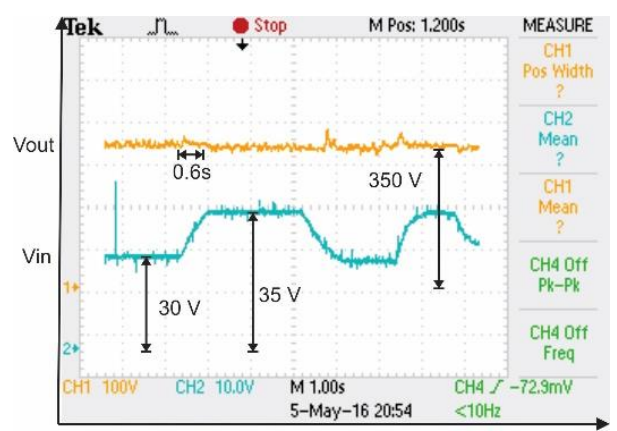

Konverter DC-DC rasio tinggi berbasis pensaklaran kapasitor dan induktor terkopel mampu mempertahan kan tegangan ouput ketika tegangan inputnya diubah dari range 30-35 V. Hal tersebut dibuktikan pada gambar 14 yang menunjukkan gelombang pengujian tegangan output konstan ketika tegangan inputnya diubah.

\section{KESIMPULAN}

Berdasarkan pengujian yang telah dilakukan terhadap simulasi maupun implementasi Konverter DC-DC rasio tinggi berbasis pensaklaran kapasitor dan induktor terkopel untuk aplikasi pada photovoltaic dapat disimpulkan menjadi beberapa hal sebagai berikut.

1. Rangkaian Konverter DC-DC rasio tinggi berbasis pensaklaran kapasitor dan induktor terkopel dapat menaikkan tegangan dengan rasio konversi yang tinggi. Pada implementasi alat didapatkan rasio konversi hingga 12 kali dengan duty cycle $0,4878 \%$.

2. Hasil dari simulasi dan implementasi alat telah sesuai dengan teori yang telah dibuat. Hal ini ditunjukkan melalui pengujian yang telah dilakukan.

3. Implementasi alat pada rangkaian konverter memiliki rata-rata efisiensi yaitu sebesar 86,01\% dengan efisiensi tertinggi pada pembebanan 40 Watt yaitu mencapai $91.73 \%$.

4. Sistem kontrol duty cycle menggunkan PI telah bekerja dengan baik terbukti konverter mampu mempertahankan tegangan output dengan tegangan input yang berubah.

\section{DAFTAR PUSTAKA}

[1] V. Scarpa, S. Buso, and G. Spiazzi, "Low-complexity MPPT technique exploiting the PV moduleMPP locus characterization," IEEE Trans. Ind. Electron., vol. 56, no. 5, pp. 1531-1538, May 2009.

[2] Ashari, Mochamad. "Sistem Konverter DC". ITS Press. 2012

[3] R. J. Wai, L. W. Liu, and R. Y. Duan, "High-efficiency voltageclamped DC-DC converter with reduced reverse-recovery current and switchvoltage stress," IEEE Trans. Ind. Electron., vol. 53, no. 1, pp. 272-280, Feb. 2005.

[4] B. R. Lin and F. Y. Hsieh, "Soft-switching zeta-flyback converter with a buck-boost type of active clamp," IEEE Trans. Ind. Electron., vol. 54, no. 5, pp. 2813-2822, Oct. 2007.

[5] R. J.Wai and R. Y. Duan, "High step-up converter with coupledinductor," IEEE Trans. Power Electron., vol. 20, no. 5, pp. 1025-1035, Sep. 2005.

[6] T. Dumrongkittigule, V. Tarateeraseth, and W. Khan-ngern, "A new integrated inductor balanced switching technique for common mode EMI reduction in high step-up DC/DC converter," in Proc. Int. Zurich Symp.Electromagn. Compat., Feb./Mar. 2006, pp. 541-544.

[7] Yi-Ping Hsieh and Jiann-Fuh Chen," Novel High Step-Up DC-DC Converter With Coupled-Inductor and Switched-Capacitor Techniques for a Sustainable Energy System" IEEE Trans on Power Elwctronics, Vol. 26, No. 12, December 2011 